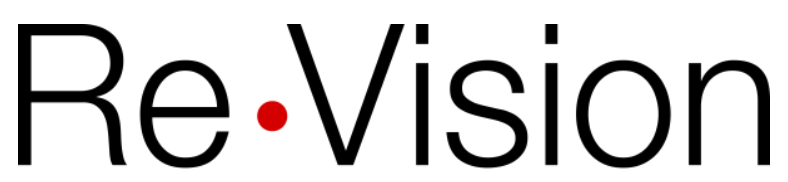

UNIVERSITY

ofGUELPH

The Centre for Art and Social Justice

\title{
Co-emergence: an art-full dance of inquiry into artists' experiences of making art
}

Gail J. Mitchell

York University

Carla Rice

University of Guelph

Victoria Pileggi

University of Guelph

This is an Accepted Manuscript of an article published by Taylor \& Francis in Research in Drama Education: The Journal of Applied Theatre and Performance on August 16, 2018, available online:

https://www.tandfonline.com/doi/full/10.1080/13569783.2018.1507730

\section{Recommended citation:}

Mitchell, G., Rice, C., \& Pileggi, V. (2018). Co-Emergence: An art-full dance of inquiry into artists' experiences of making art. Research in Drama Education: The Journal of Applied Theatre and Performance, 23(4). 563-581. https://doi.org/10.1080/13569783.2018.1507730 


\title{
Co-emergence: an art-full dance of inquiry into artists' experiences of making art
}

Gail J. Mitchell, Carla Rice, and Victoria Pileggi

\begin{abstract}
This paper offers an account of how women and gender non- conforming people living with mind/body differences connected and changed during a project of creating a dramatic performance intended to shift understandings of disabilities and differences for various communities, including health professionals. Insights from interviews with artist participants are presented in three themes: collective unearthing, carefully bringing forth with others, and embracing the newly tangible. Our insight at this point is that disabilityaffirmative artistic processes create an inter- and intra-relational space that invites generative learning through self- and critical reflection.
\end{abstract}

\section{Keywords}

Embodied difference; devised theatre; artful pedagogy; disability arts practice

This paper offers an account of how women and gender non-conforming people living with mind/body differences connected and changed during a project of creating a dramatic performance intended to shift understandings of disabilities and differences for various communities, including health professionals. By gender non-conforming, we mean persons who do not act or live according to male-female and masculine-feminine binaries and stereotypes. We describe the effects of immersion in creative processes as recounted by artists (performer-participants) themselves. Our paper is thus animated by a central question: What can artistic processes teach creators? We ponder the affects and insights that emerged in the creative process for the eight performer-participants. We build on insights articulated by several others, such as Kramer and Fask (2017), Mackey (2016), Perry (2011), White and Belliveau (2011), and Yassi et al. (2016), about the ethical issues and transformative processes that surface when researchers and 
artistic leaders collaborate to represent experiences of persons who have traditionally been excluded, sensationalised, and misrepresented - placed on display and/or hidden away. The project was marked by unexpected, unfamiliar, and sometimes turbulent waters. But emerging from the unknown and turbulent spaces were insights and images that changed all performer-participants in unanticipated ways. We begin with the image and story of the Fishbird by performer-participant and visual artist Janna Brown (Figure 1).

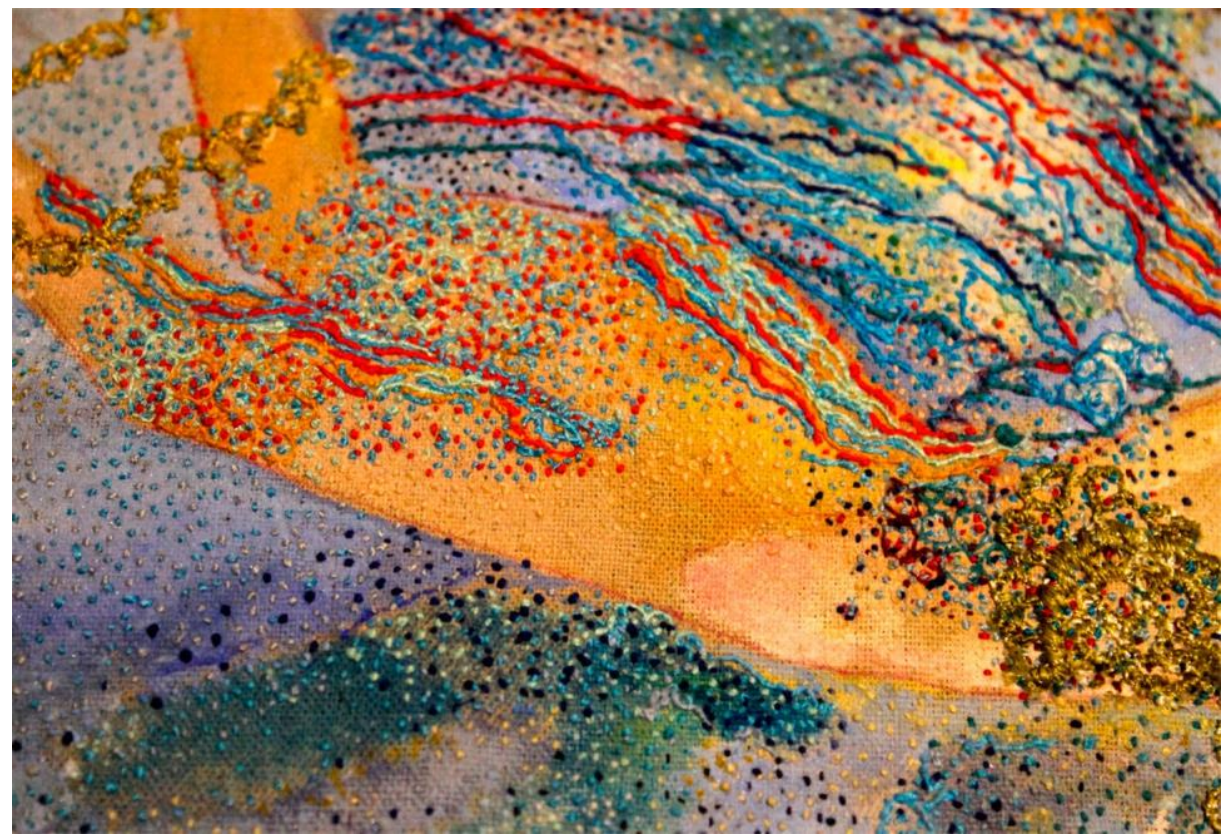

Figure 1. Fishbird

Fishbird

In a previous life, I was a fishbird.

Yep. A swimming, flying creature

that sinks to the bottom of the ocean

and feels light fracture through the waves.

In a previous life, I would go to the middle of a big room upstream

every Tuesday, Wednesday, Friday, Sunday, and repeat.

I was quiet when I was asked.

I sat in pews too hard for my little frame. 
I bowed my head and looked for sunlight under my eyelids during prayer.

In a previous life, my father stood at the front of that big room

every Tuesday, Wednesday, Friday, Sunday, and repeat.

The first naughty word I remember was caress.

I found it in a Reader's Digest, and then a hardcover dictionary.

And I shut my door with the pleasure guilt when I found it.

Really, it was the sound of the $S$ that got my attention.

Like kiss and miss. Or bless or piss.

In a previous life, the double $S$ got me in all the wrong places

And the big room held me while light and a double $S$ took me deeper

than the ocean floor.

And so, in a previous life

I left that big room and the Tuesday, Wednesday, Friday, Sunday, and repeat.

By then I had drank my fill of that water

And I had a taste for air,

And for the days,

And for space around my thoughts.

So now, I bow my head to look for signs and shadows

And sunlight under my eyelids

And a different kind of $S$.

-Janna Brown

'To get it, to understand, is to experience meaning. It is to be able to go on.'

-Jan Zwicky (2017)

\section{Background of the project}

The artistic undertaking discussed in this paper is affiliated with the Re・Vision Centre for Art and Social Justice, a research creation centre that since 2012 develops multimedia methodologies and storytelling workshops in which women and gender nonconforming people living with disabilities, and healthcare providers, create new and multiple representations of embodied difference (Rice et al. 2015). These workshops enable story makers to create multimedia stories through the genres of drama and 
video. Re•Vision's approach is unique in that we work with members of aggrieved communities and allies, both of whom may be located in systems implicated in people's oppression. We build storytelling workshops led by disability-identified artists to (temporarily) shift intersecting power dynamics operating in people's lives; and drawing on activist art traditions, we approach art not only as research but also as activism - in its power to disrupt norms, create understanding, and open possibilities (Felshin 1995; Perry 2011; Platt 1997; Raphael 2013; Rice et al. 2016). Our project explores the possibilities of the creation and presentation of disability and non-normative art to disrupt stereotypical understandings that create barriers to healthcare and inclusion in the broader society. Since its inception in 2012, Re•Vision has run 14 filmmaking and 12 drama workshops with disability-identified artists and non-artists as a means of conducting and disseminating our research. In the following pages we describe the larger multi-site research project from which this paper emerged and then present themes that represent performer-participant experiences of creating a theatrical piece to engage with health professionals.

Within the Re•Vision Centre for Art and Social Justice, a specific multi-site research project funded by the Canadian Institutes of Health Research was devised with the following objectives: i) generate new knowledge that might influence clinical concepts of disability and difference; ii) facilitate and analyze knowledge engagement/exchange processes between health practitioners and women with differences using digital storytelling and research-based drama; iii) evaluate the impact and efficacy of providers' involvement in the creation of arts-based knowledgeexchange tools with women living with differences for shifting clinicians' self-reported attitudes, responses, and clinical competencies; and iv) evaluate the impact of viewing arts-based knowledge exchange outputs on practitioner audiences' self-reported attitudes and perceived self-efficacy in clinical interactions. The research inquiry involved workshops where non-mutually exclusive groups of stakeholders - disabled people, health providers and academics - 'talk back' to received representations and make new meanings. Our drama workshops engaged disabled artists and academics, including trained actors and non-actors, and culminated in an immersive devised theatre piece titled Small Acts of Saying (hereafter referred to as Small Acts). Small Acts 
included the performance of the Fishbird poem by Janna Brown and other untitled spoken word pieces written by performer-participants.

Small Acts features stories of health and social encounters. The play uses few props and is designed to be staged in diverse spaces. In some performances, actorstorytellers carry their medical files as they move through audiences; and they periodically stop and perform their stories before audience members as a way of 'turning the tables' on providers who may now or in the future make decisions that have implications for disabled people's lives. In others, the participant-performers sit in a row facing the audience and step or roll forward to deliver their monologue when summoned by officious voice off-stage, akin to a medical professional summoning a patient from a waiting into an examination room. To capture the impact of this work, we generated an archive of Small Acts performances, conducted pre and post workshop interviews with cast members on their experiences of creating and performing disability art, and conducted post performance interviews and surveys with audiences on their experiences of the work performed.

Our research team wanted to understand how engagement with the arts, as makers and/or audience members, might change disabled people's and health care providers' perspectives on disability and mind/body difference. As we began to recruit participants in Canada's most populated province of Ontario, we interfaced with disability-identified artists interested in our work. Until recently, few spaces have existed in Ontario where disability artists could receive professional development and exhibition/performance opportunities. Because of this gap, our project attracted disability artists who seized our workshops as spaces to access training and peers. In this cultural context, the theatre workshops came to fill a key gap in Ontario's disability arts movement as we provided free, accessible arts training led by disability artists for disability artists. The way that the research team members and the disabilityidentified participant-performers recognised the theatre piece as art rather than as strictly a research output or knowledge mobilisation tool provided the conditions for which disability arts community could be developed within a culture in which accessible, disability-positive art-making spaces rarely (though increasingly) exist (Chandler et al. 2018). 
From the onset, the researchers intended the theatre piece, Small Acts, to be experiential and experimental: we aimed to workshop performer-participants' encounters with the health care system; to bring together iterative accessibility practices with the devised theatre process; and to produce an aesthetically sophisticated (though not necessarily polished) piece that was strong enough to hold the engagement and imagination of healthcare providers. However, the director and participant-performers did not always share in these aims. Some performer-participants wanted a platform through which to advance their artistic careers, others a space to find and enact disability arts community, and still others the opportunity to be part of a research project that could disrupt ableism in healthcare. The various aims and interests were juggled through the workshops with performer-participants who told their stories. Stories were woven together to create a unified, presentable, theatre piece that accomplished artistic goals linked with devised theatre aimed at opening space for critical thinking (Perry 2011).

In order to create a coherent artistic piece, the director used metaphor in rehearsals to help performer-participants think of their performance as a gift that was prepared, wrapped up, and presented to the audience as an offering for them to receive as they wished. This metaphor of gift was made a tangible anchor in performances through rectangular medical 'file' boxes that storytellers filled with meaningful personal items and unpacked during their monologues. There were tensions at times as clashes surfaced among artistic, accessibility, and research goals. For instance, the director edited participant stories to create the coherent vision of a waiting room from which each performer-participant delivered a performance that contested dominant narratives of disability. Performer-participants, as research participants, had expectations that their stories would remain their stories, but the director required a coherence in how Small Acts would come together with an integrity to the artistic vision. These tensions remained unresolved throughout, but they did not derail the project.

In 2015, the actors performed the work for diverse audiences of healthcare providers and trainees in five spaces: a hospital cafeteria, a hospital seminar room, two university lecture halls, and an arts hub. Discourses about disability affiliated with the dominant culture of healthcare commonly circulate throughout these spaces. Aligning 
with the tenets of devised theatre and other experimental forms, we drew on 'the discourses of the dominant cultural forms to critique them and re-create or "design" new meaning' (Perry 2011, 72). While researchers increasingly have documented the impacts of research-informed drama among audience members, to date, almost no research has investigated the effects of immersion in creative processes on artists themselves. This paper then shifts from creating and attending to spaces for critical pedagogies with spectators to attending to the benefits and teachings that Small Acts performer-participants identified in their interviews with researchers.

At its heart, our work aligns closely with Perry's explication of critical pedagogy and the arts-based spaces for critical thinking that emerge within 'the creative process, the performance event, and engagement with the emergent spectator' $(2011,63)$. We know that art can teach; our research is based on the belief that art made by disabled and differently embodied people provokes healthcare providers to understand disability and mind/ body difference in new and different ways (Rice et al. 2016). Yet, rather than asking what this work teaches audiences, we have been galvanised by our interviews with Small Acts performer-participants to think through the complexities of what artistic processes can also teach disability-identified artists and how immersion in creative work might teach in non-didactic ways to indeterminate but also, as the artists themselves often describe it, to transformative ends.

\section{Context and methodology of informing creation of Small Acts}

We situate Re•Vision's work in the methodological traditions of critical arts-based research (Conquergood 2002; Perry 2011) and participatory action research (Kemmis, McTaggart, and Nixon 2013) and consider these traditions as complementary insofar as they each endorse participatory, political and process-oriented principles/approaches (Rice and Mundel 2018). Our methodology also draws from and contributes to a set of emergent approaches in the arts referred to as disability arts practice. Disability arts practice orients to ways of making the arts more accessible - both to disabled artists and audience members - and understands such art not only as a tool for social change, but as of inherent aesthetic interest and value (Raphael 2013). Jacobson and McMurchy define disability art as 'a vibrant and richly varied field in which artists with 
disabilities create work that expresses their identities as disabled people' $(2010,1)$. Methodologically, we draw from aesthetic theory and engage intensively with disabled artists and communities, 'making our processes and outputs more than manifestations of creativity, or a means of therapy - as disability art has often been conceptualised - but disability artistic and activist processes and "disart" creations in themselves' (Rice et al. 2016, 2).

Our project recognises that disability art can take many forms and that community artists can create activist art, as can professional artists (Kuppers 2011, 2016). We distinguish arts-based research from professional or studio-based arts in recognition of differences in the purpose and quality of work created by studio-based artists and that of others without formal training or long-term immersion in artistic practice (Cahnmann-Taylor 2008). Our work thus supports and initiates both professional/ studio-based and participatory/community-based art practice and seeks to blur boundaries between these worlds by bringing artists, academics and community members together to examine the possibilities of art for knowledge generation, cultural creation, and social change (Rice et al. 2017). The outcome of the theatre-based project was the creation of Small Acts.

\section{Small Acts: devised theatre}

Small Acts was informed by devised theatre as articulated by Perry who links devised theatre with pedagogy as 'knowledge in the making' and as 'sites for productive critical pedagogies' $(2011,63)$. Although devised theatre can be considered a methodology to create and engage, our work can also be thought of as an 'arts for social change' (ASC) project (Yassi, Spiegel, Lockhard, Fels, Boydell \& Marcuse), which is understood as 'art that is created collectively by groups of people (who may or may not self-identify as artists) about what matters to them, through arts or dialogic processes that are facilitated by an artist or group of artists' $(2016,201)$. Mackey $(2016)$ offers a view of devised theatre projects involving researchers, artists, performers, communities, and audiences as 'polyphonic conversations' that are at times erratic, intense, ambiguous, strained, and generative (p. 478). The fittingness of devised theatre is supported by Burton who noted that, 'collaborative, collective, and devised theatre 
practices, provide alternatives to traditional structures and hierarchical processes, which historically have excluded some groups and privileged others' $(2017,40)$.

White and Belliveau (2011) address complexities for researchers using artistic processes for inquiry and identify some of the tensions that we experienced in this project. These tensions include attending to researchers' responsibilities to preserve the dignity of performer-participants and ensuring the integrity of performer-participants' stories and processes of consent throughout the experience of making art to engage with audience members. As researchers, we were implicated and involved in this devised art project even though we did not desire to control the artistic process that would unfold. The issue of control and intermittent distress of performer-participants added to the project's intensity and surfaced questions such as: whose story is being created? Who should have the final say - if there is such a thing - the director, the researchers, the performers/ storytellers?

Working with a group of eight performer-participants, our devised theatre project involved two directors hired by the research team in order to create Small Acts. After working briefly with a non-disability identified director, Re $\bullet V i s i o n$ researchers engaged a disability-identified director who had a long history of collaborating with disabled actors and non-actors, including on projects using theatre. The change of director followed from our increasing awareness, as the process unfolded, of the need for a director with skills in disability arts practice. The original director-playwright worked by extracting and molding participant-performers' stories into a polished piece created and owned by the director; however, given the representational history of disability as spectacle, the participant-performers wanted and needed a more creative/collaborative co-ownership approach.

There were also tensions among the art director and researchers linked with control of the artistic play. The researchers had invited performer-participants to be involved as research subjects who would contribute to the art creation process. Researchers and some performer-participants wanted a collaborative process, while others wanted a more directive artistic leader to decide on process and product. For some, collaboration suggested an onerous process of working through unnecessary details of personal experience. The performer-participants were research participants 
not hired workers who could be removed from the process. These tensions required discussion and willingness to find the best way forward given the context and questions at hand. Persons who wanted to control the art-making process used the notion of art for art's sake, not art as therapy, as a reason to exert influence/dominate the process. The director expressed concern that if the performer-participants were going to have agency over the script and over the performance, then it would be art as therapy and not art for art's sake. Adding another layer of complexity, the researchers wanted to ensure that performer-participants were respected and listened to and that they felt safe to speak and move within the creative process. In this scenario, everyone involved worked with some constraints.

The constraints of the research process included the budget available for creating the arts piece, the time line of availability for the art director and performerparticipants, the need to keep the research on a time line consistent with the funding organisation, the multi-site touring of Small Acts, and the large research team with members scattered over several hundred miles. The choices available to researchers included the hiring of artistic director, decisions to help ensure performer-participants experienced an ethical process of collaboration, and determination of the length of time for production. The choices available to the director included how to engage with performer-participants and how to conceptualise the overall vision of the art. The choices available to the performer-participants included making decisions about what to reveal, how to engage, and what feedback to give on the artistic vision and on the research goals. Researchers were bound by the ethical process to work within everyone's expectations and desires for the project; the goals for the product being created; and the complex realities that sur- faced during the creative process.

\section{Our devised theatre process}

The director and performer-participants, all disabled people with different attachments to the artistic process (some were trained actors and storytellers and some were not), worked together with and through their differences in research and artistic experiences to become a connected artistic community. During the creation period that took 18 months of immersion and rehearsals, performer-participants wrote and told their 
stories of living with difference and encounters with the medical system. In the writing and telling, the artistic director would question, probe, clarify, and provoke in order to move the group toward a coherent vision for the project. The performer-participants enacted Perry's 'collaboration in ... performance creation, [where] participants are at once learning through doing, comparing, and contemplating each other's input (critique) and at the same time troubling and unraveling knowledge, experience, and subjectivity' $(2011,68)$. Performer-participants travelled to healthcare, educational and arts settings to present the final piece, Small Acts, in eight 45-50-minute performances, which were followed by question and answer sessions.

\section{Data collection/analysis}

To document experiences of creating Small Acts, seven performer-participants completed an individual interview at two points in the project's process. The first took place soon after the first director left the production, prior to the second director's involvement. The second interview was held within six months of the final performance. A research associate conducted these in person or via telephone, depending upon the performer's preference, and they lasted between 30 and 90 minutes. Around the time of the first interview, we held two focus groups with the entire cast and some research team members to capture insights about our process. These focus groups were not included in the analysis for this paper. Instead, we reviewed data from pre- and postworkshop interviews.

The pre-interview was split into two parts, the first exploring performers' experiences of living with mind/body difference, and the second probing their experiences related to the collaborative creative process of Small Acts. In the first part of the interview, participants responded to questions regarding social perceptions of women/gender non-conforming people with mind/body differences, including attitudes that participants have encountered in healthcare and strategies they've drawn on when dealing with healthcare providers. Interviewees reflected on what they know and understand about living with disability that they think others would benefit from hearing and knowing. In the second part, we inquired about what drew performers to the project, what they were trying to capture in their monologues, what it was like to participate in 
the project, what goals they had in mind when they signed on as a troupe member, and what they were learning or how they were being impacted by the project. Postinterviews probed lived experience and creative process. The interviewer asked performers to evaluate the process narratively, to identify what they learned from exploring experiences of embodied difference through theatre, and to reflect on risks and rewards associated with devised disability arts theatre. All were invited to expound on memorable aspects of and insights taken from the performances and creative process, what they might do differently as a result of their participation, and what the team could do to enhance the experience of performing in a production like Small Acts if it were revived in the future.

We analysed the interview data thematically using NVivo software. Two principal investigators, the project manager of Small Acts, and the research associate met to generate broad themes that emerged through their witnessing of focus groups, rehearsals and pro- ductions, and through their independent reads of interview transcripts. The associate then isolated and assembled quotes under umbrella themes. We revisited each transcript a third time to identify additional patterns in performers' narratives. These secondary emergent themes were examined alongside the original themes and both sets of themes were compared, streamlined, organised into primary and subthemes, and related to each other.

\section{Themes of co-emergence in the art-making process}

We focus on themes that emerged through descriptions offered by the performerparticipants in addressing what happened for them in the creation and performance of Small Acts. We have offered Janna's Brown's poetic Fishbird monologue at the beginning of this paper as an example of the art that was created as part of Small Acts. To carry on the process of co-emergence through art for this paper, we commissioned Brown to render her thought-provoking Fishbird into a visual form. She created a delicately textured image of a floating female figure using vivid blue, green and aqua paint, found lace fabric and multi-layered and coloured embroidery thread. Drawing on the performer-participants' interviews, we offer three themes - collective unearthing, carefully bringing forth with others, and embracing the newly tangible - that surface from 
our analysis of the pre- and post-interview transcripts with performer-participants in Small Acts.

\section{Theme one: collective unearthing}

The first theme, collective unearthing, relates both to the opening to discovery described by performer-participants, as well as the shared endeavour of seeking to find something together. It is interesting to notice the feelings that actors expressed: the moments of unexpected laughter, the uncertainty, the willingness to go with the flow of not knowing. One performer used the word 'unearthing' in describing this process. All expressed the intensity of being together to participate in a joint inquiry that was simultaneously prescribed and open; prescribed by the research process and goal of creating space for education through art, while open to the collaborative process of creation and meaning making. The director's and performers' shared commitment and purpose in coming together to create art opened up a generative relational space for this collaborative unearthing. Moreover, the process of finding, sifting, sorting, and keeping the emergent nuggets of value occurred with and through the performerparticipants' felt and expressed appreciation for the opportunity, still all too rare in an ablest (art) world, for disabled artists to come together in accessible spaces to engage in disability arts practices and produce disability art. For some, the opportunity to collaborate with other disability-identified artists was the catalyst that fueled the collective unearthing process. Participants describe their collective unearthing as follows:

Participant 2: There was something that we created together where we could laugh at things that in any other context wouldn't be laughable or we wouldn't actually want other people to be laughing ... Most of us were, didn't have the framework so it was learning a new language about how to take the inspiration and the lived experience and how to offer it. [...] [L] like we're not putting on this act, we're actually like coming into ourselves.

Participant 3: I just remember the feeling of like walking into the room and being completely like not sure what was going to happen but then I just had to 
go with it. And that's something I'm not used to doing, I'm used to, you know, planning everything out and nothing kind of left to chance. So that was very new and I'll definitely remember you know, just the variety of activities that I randomly had to participate.

Participant 6: People had non-normative bodies and non-normative ways of moving so you would have to adapt. But out of adaptation we produced something new ... And so disability was always producing something that was different and wonderful ... but it was productive, right? If you get a group of people together whose experience of the world is not, you know, the typical, is not the normative, and then kind of riffing off each other, you end up with some- thing that's very remarkable and very unique because they're playing off each other, and their creative juices are flowing.

\section{Theme two: carefully bringing forth with others}

The second theme, carefully bringing forth with others, relates to the concern and care that the performers shared, each for the other and for themselves. They spoke of trust, safety, gentleness and tenderness; of creating and holding space for sheltering their stories; of enacting and maintaining an accessible physical and emotional space as part of disability art practice; and of recognising that in telling their stories, there were, and would be, con- sequences. Performers described the affects - the tensions, wounds, and regrets - of relating in ways that violated the intimate accessible space they together created. Many spoke at length about the challenges sometimes associated with bringing together a group of women and gender non-conforming people living with different embodiments, disability histories and needs, and the sensitivity required to hold space as they and their colleagues immersed themselves in creative space. As the following quotes attest, making space accessible to all involved required that they negotiate their terms of being together as a constant iterative process.

Participant 2: I think that disability poses a wonderful, like making art, disability-based art poses a wonderful and treacherous puzzle. How to make 
meaning out of experience and then how to make that experience tangible for an audience. And the conundrum that I saw playing out in this process was that across experiences I noted that we're often obliged, in order to access resources or, or even to like sort of counter bio-medical perspective that might be imposed, we have to make real enough our experience of body in order to be taken seriously ... I think I'm more aware of how I occupy space and how I express questions. I think that sort of came up for me during the process is just a greater awareness of how the delivery of feelings can affect other folks.

Participant 8: I kind of had underlined for me - yet again, right - the way in which disability experience itself within disability is so stunningly diverse, right. Like the things that I under- stand about disability, the way I experience disability, the way I embody disability - you know, some people don't even want to call it disability, right, they don't like that word. ... I was with a group of disabled women who variously identify themselves in different ways in terms of their embodied differences, and you know, those conversations around what it means to be the physical person that you are. And also some of those differences, you know, contributed to a certain level of heightened emotional experience and intensity that also was part of the whole kind of how do we accommodate each other in our different ways of being, right? It was intense; sometimes enjoyably intense, sometimes disturbingly intense, sometimes.

As participant-performers 'learned through doing, comparing, and contemplating each other's input (critique) and subjectivities' (Perry 2011, 68), they imagined different ways of seeing and being.

\section{Theme three: embracing the newly tangible}

All participants described being changed by the creative process - and the change, though unique to each, collectively involved the experience of embracing something new. While all performer-participants described multiple learnings - including renewed optimism in producing creative work, development of new skills, and 
generation of artistic self-confidence - the majority highlighted disability-specific insights that they gleaned through the process of collective creating. For many, collaborating with other disability- identified artists provided space to think anew about embodied disability experiences, to make alternative meaning of those experiences, and to claim disability in new ways. These insights surprised almost all participant-performers; given the diversity of their reasons for joining Small Acts, from advancing their artistic practice to changing health- care, most did not expect to engage in so much critical and embodied learning about self and society. New wounds and new risks surfaced as the performers embraced the newly tangible. Some quotes describing these processes follow.

Participant 2: One of the monologues that I created ... it was quite abstract but at the same time it helped me to identify the ways that a number of my experiences intersected and informed my disability ... I didn't sort of feel comfortable presenting the whole package really until, up until this process I think. And maybe I didn't fully reveal it even but I was able to see the nuances and the connections better for myself. And just to be able to dwell in it a little bit better.

Participant 4: I've never done anything like it before and I realized once I walked in that I had to you know, be vocal about you know my disability. I had to say what it was, I had to talk about it. I had to be honest ... it was really a chance to open up to my disability for myself because for a very long time I was very like closed off about it and if people asked, you know why do you walk funny and things like that, I would just sort of l'd be like none of your business. I thought you know, this would be an opportunity to teach people about my experiences, but to also sort of let myself learn to be okay with having a disability and just accept it and be able to say like, I have cerebral palsy ... it was kind of it was to benefit other people but it was also just for myself as well.

Participant 6: I got a sense of the perspective and the range of perspectives being told ... and realizing that a position that I sit in is a very privileged one, 
and um that l've been quite reticent to take on the disability label, if you like, and to speak from that position. And a lot of it has to do with um a fear of stigma.

Participant 8: The project was very valuable because it forced me to think about the meaning of [my disability] because I'm sort of getting along as best as I can ... [It] called on me to really seriously think about what embodiment means ... and how we embody in different ways.

\section{Discussion of findings}

The three themes identified from performer-participants describing their experiences in making devised theatre offer affirmations of previous findings, as well as nuanced insights that challenge assumptions of discourse and habit. We begin with connecting the themes- collective unearthing, carefully bring forth and embracing the newly tangible - with previous research.

\section{Collective unearthing}

The simultaneously personal and shared process of discovery and creation described by Small Acts performer-participants has been reported by numerous researchers and artists (see Burton 2017; Camic, Baker, and Tischler 2016; Cox, BrettMacLean, and Courneya 2016; Perry 2011; Sagan 2017). The theme is consistent with insights from Burton (2017) that collaboratives bring strength in unity and greater potential for new ideas and solutions. Anderson et al. outline the health benefits of a collaborative drama programme for performers and describe a project where older adults and university students 'work together to develop ensemble-created plays' (2016, 2 ) that they perform numerous times a year. The researchers developed this as a participatory action research project and interviewed participants about their experiences of collaborative dramas. Both older and younger performers indicated that their project created a unique space that released them from usual ways of thinking and interacting. Performers reported learning, growing and building relationships through processes of storytelling and theatre making. Unlike our themes, fun and playfulness 
were reported as critical to this project in contributing to learning and creativity.

Dupuis et al.'s (2016) community-based, arts project, Cracked: New Light on Dementia, brought together persons with dementia, their family members, visual and performance artists and researchers to disrupt the dominant discourse of dementia as tragic; a goal that aligns with our intentions for Small Acts of disrupting received narratives of disability as a problem in need of cure. In their reflections, Dupuis et al. (2016) consider the bringing together of diverse, individual experiences as a driving force behind cultivating a safe $(r)$, creative space for dialogue and critical interrogation, which ultimately enabled intimate connections to form amongst the project's players, and for deep understandings of self and other to surface. Participants in the Dupuis et al. study yielded and sustained these emergent relationships with self and other by hearing and sharing personal stories and letting go of fear, expectation, invisibility, and previously-held assumptions. Together, these conditions culminated in production team members becoming aware of their own and others' vulnerabilities and capacities, and imagining new ways of being with and relating to one another. Many of these very same themes and discoveries emerged in the interviews with the performer-participants of Small Acts. These collective revelations are vital to the fabrication of a discourse or pedagogy of possibility (Dupuis et al. 2016; Kinsella 2003) related to mental and physical differences by community members them- selves, speaking directly back to the dominant discourse of difference as misfortune and in need of repair.

According to Nedlund and Nordh (2015), the experience of self in a collective brings into consciousness concepts such as solidarity, social membership, and being an active member of a larger community. In moving toward identification in and through difference by sharing and co-witnessing experiences, as the performer-participants did in Small Acts, everyone can name and revise their conceptions of people, cultivating a new and more positive sense of self in the process. The notion that community art can culminate in wider social change stems in part from Freire's (1972) Pedagogy of the Oppressed and further advanced by Augusto Boal's in his Theatre of the Oppressed (2000). Freire's critical pedagogy inspired politicians and community members to strive for social change by exposing oppressions and possibilities. Similarly, for Boal, the theatre is a platform for a rehearsal of life; a means of preparing for responses when 
specific situations arise, and allowing people in communities to proactively explore techniques and alternative languages in order to achieve emancipation. Each person in a production is a 'spectactor' (Lariscy 2016), one who both observes and acts, and over time, the boundaries between individuals fall away to allow for their synergistic convergence as a community of people, working together to 'solve problems, share joys, learn about themselves, and take charge' (Howard 2004, 221). Inspired by Freire and Boal, Sajnani (2012) proposes that through collective reflection and shared, iterative dialogue, social action can be thrust forward. While the production of counternarratives related to disability and difference was a goal of the theatrical performance of Small Acts, the presence of reflections on the coming together of the individual performer-participants in their own narratives represents the profundity and power of the principles of the Theatre and Pedagogy of the Oppressed at work.

The work of Julia Gray (2016) also proves useful when considering a more relational view of creating art. She suggests that a theatrical ensemble can become a 'place of embodied possibility' (p. 70-71) through performers' intentions of being in sync, and that this space is continually re-invented as the individuals in the ensemble shift and grow within it, using art to extend their bodies and to sense and explore experiences in their lives. We propose that the process of developing and delivering Small Acts served a similar purpose and facilitated the creation of a similar space; the storyteller-performers and director alike experimented widely with the method and their bodies and flourished as a result, both as individuals and an ensemble. Just as Gray reflects on the emergence of interdependence, trust, letting go and following the lead of others in her ensemble, the seven Small Acts performer-participants referenced similar experiences in working together to produce this novel disability arts piece.

This literature echoes Johnson and Stanley's (2007) claim that a theatrical group or team can provide valuable insights for its members on the centrality and necessity of reciprocity. It also parallels Carley's (1996) training article that draws upon theatrical productions to inform team-building processes in business and other realms. Namely, Carley suggests that a successful theatrical production rests on the success of team effort, produced through conditions including, but not limited to: the distinct and unique contributions of directors, actors, and other crew members; a sense of mutual trust, 
reliance on and admiration of one another; a framework in which all can freely and creatively self- express; and the engendering of mutual respect, belonging and selffulfillment. The theme of collective unearthing, described above, encompasses many of these catalytic conditions.

\section{Carefully bringing forth with others}

The idea of creating spaces of safety and trust has been reported in research on arts-based processes (see for example, Anderson et al. 2016; Gray 2016). Participantperformers in Small Acts did describe the importance of a safe( $r)$ and non-judgmental space. And, like participants in the Anderson et al. study, Small Acts performerparticipants recall the work of the collective as enhancing their feelings of compassion towards one another. However, the challenges of safe spaces were also brought to bear in Small Acts. Rooted as it was in the tradition of devised theatre, processes adopted in building the final theatrical piece included: inviting all performers to play a role in setting the terms of their engagement with each other and in determining the play's devising and direction; and assigning the artistic director directorial responsibility in safeguarding those terms and in determining the overall aesthetic presentation of the final play. Challenges developed among participants as issues of diverging desires for direction, power, and control surfaced.

Golosky (2017) explicates the complex layers of the word safe and what it might mean when traditions of power privilege some voices/perspectives over others. In this project, powerful voices/perspectives of directors, researchers, and other professionals regularly engaged with the women and gender non-conforming performer-participants living with mind/body differences. Group members described witnessing transgressions of 'safety' and, it is most interesting that these transgressions were ablest in nature, given that the group was united by their living with difference. From a disability arts perspective, we acknowledge the need for arts researchers to think more carefully about 'voice' and power dynamics in relation to non-verbal members of the disability community (though there were no non-verbal performers involved in Small Acts.) We excavate these complex issues of power in another paper. In the end, the theme of carefully bringing forth with others predominated in artist transcripts. 
Boydell (2011) comments on how performers may experience the emotional ramifications of engaging with challenging subject matter; in Small Acts, however, rather than those without lived experience vicariously performing disability, performers with situated realities and lived experiences were re-exploring and re-presenting their own experiences and emotions (Rice, LaMarre, and Mykitiuk 2018). Reconciling performerparticipants' various physical/emotional accessibility requirements and often powerful affective responses to the personal material being mined was further complicated by the some- times conflicting research, aesthetic, and political aims. At times, the commitment to present an aesthetically sophisticated piece (an integrated vision of performance that engaged spectators at individual tables situated in a crowded cafeteria, for instance), contravened with the mind/body realities of some performers. These tensions took shape through constraints imposed by the (neoliberalized) research apparatus itself, which necessitates the successful production of a polished art piece within a prescribed period, imposing pressures on performers and directors to attend all rehearsals, to be on (normative) time, and to tell stories to dramatic effect, etc. (Rice \& Mundel, forthcoming). These constraints and tensions surface the limits and possibilities in attempting to undertake disability arts using the devised theatre method in arts-based research.

This process of performers negotiating their terms of engagement surfaced deeper conundrums related to paradoxes surrounding concepts of accessibility and inclusion. Mitchell, Snyder, and Ware (2014) point out how social (including artistic) spaces where there is an effort to 'unveil architectural, aesthetic, and moral spaces of inclusion' and appear open to everyone nevertheless 'paradoxically, strictly police ways of being different for the bodies they include' (p. 298). They argue that despite people's best efforts and intentions to create accessible spaces - and in truth, because of them, insofar as our commitments set the terms for preferred and dis-preferred ways of being in a space - we inevitably exclude those who have difficulties embodying the terms, however expansive these may be.

This suggests that accessibility and inclusion are elusive endpoints that 'cannot be mandated under universal design best practices because difference cannot be fully anticipated, planned for, known, or mastered' (Rice et al. 2015, 523). Rather than 
framing accessibility and inclusivity as endpoints, our experience with Small Acts indicates that these goals might more productively be approached as iterative processes in disability arts, and that failures to enact or accomplish them that inevitably occur along the way, be embraced as a necessary part of coming to know each other in and through our differences. Performer-participants' insights point to a critical learning for us as researchers: that the value of disability arts practice, in part, lies in its striving to establish an ethic of radical openness to, and accommodation of, the other, and insofar as it adopts these principles, helps to create the conditions of possibility for creators to carefully bring forth that which was previously unknown.

\section{Embracing the newly tangible}

Academics, both within the social sciences and the humanities, are implicated in the limited conceptualisation of art, especially disability art, as therapeutic; artists, too, both seasoned and amateur, from across disciplines and genres, frame their own experiences of artistic creation as inherently 'healing'. For example, Sprinkle (1997) attributes her performance in a production by the women's art collective Carnival Knowledge, as 'a spring- board for a whole new and improved life' (p. 68). She goes on to describe the preparation for, and performance of, her monologue in the show, Deep Inside Porn Stars (an enactment of how women in the pornography industry view themselves) as inter- and intra-personally 'therapeutic' (p. 68), fueling her desire to become a performance artist. Like Sprinkle, Small Acts performers used intimate stories of their lives to create and shape their drama. Perhaps most importantly, Sprinkle says her performance art was intensely educational, and open to the learning that happened with audiences. In her collaborative projects with other porn stars, Sprinkle also described the collective care and growth that happened as women disclosed their realities in new ways and became more authentic. Sprinkle's insight into the healing nature of her work aligns with insights from Small Acts performers; while we hoped that their performance would engage and impact audiences, what we did not anticipate was the extent to which the process of creating Small Acts affected and even transformed the performers themselves. In this way, the learning of performing was transformative for Sprinkle and for our performer-participants. 
Similarly, Sajnani (2013) details the benefits of a course-based ethnographic performance project about gender, migration and citizenship as a 'therapeutic experience' akin to drama therapy, given it allowed the artists to become aware of the intersections of gender and national identities and the conflicts these engender. Through her participation in one such project, The Body Politic, Sajnani (2013) and colleagues each performed a monologue about a moment or an encounter related to their experiences as immigrant women. As a result of participating in the process, Sajnani was able to reframe difficult and conflicting emotions associated with actors' experiences as examples of 'social and political distress, effectively shifting the locus of malaise from us as individuals to us as a group living in a complex, and at times oppressive society' ( $p$. 384). This political revelation impacted the creative direction of the final monologues, allowing the artists to actively speak out against their own oppression, and to re-story challenging experiences of immigration as reflective of xenophobia and cultural stereotyping rather than as internal flaws or personal failures.

The longstanding association of art with catharsis presupposes that the sum-total of art's value lies in its ability to 'fix' that which is 'broken'. This conceptualisation of art, we argue, is not only limited but also antithetical to the aims of disability arts. From a disability activist arts perspective, 'art as therapy' rests on the faulty assumption that $\mathrm{mind} /$ body differences are problems requiring solutions and insofar as this discourse embraces dominant narratives of cure and overcoming, it discounts the very human experience of living with disability. Moreover, where the arts literature does describe transformative processes outside the discourse of therapy and cure these processes are relatively under-theorized, and lack analyses of what conditions facilitate such change. We contend that there exists a transformative aspect of artistic creation for disability-identified makers that is not wholly captured or contained by discourses of therapy, healing, overcoming and cure. This sort of transformation does not begin from the premise that $\mathrm{mind} / \mathrm{body}$ difference is pathological or defective and hence does not seek to assimilate it by restoring the body to some mythical normative state; rather than aiming to fix bodies/minds deemed broken, it is oriented towards positing embodied disability experience as a site of knowledge. In so doing, it enriches and expands disability culture and cultural meanings of difference. 
Our analysis suggests that what performers describe as therapeutic may be better understood as a pedagogy known as generative learning. Generative learning (Fiorella and Mayer 2016) is a mode of teaching/learning by which people learn to incorporate existing knowledge with new ideas through experimentation and radical openness to others/process. This idea of generative learning aligns with our insights that artistic processes transform by teaching creators about self, other, and life.

\section{What do artistic processes teach?}

The goal of this analysis was to gain insight into what collaborative creative processes teach disability-identified performer-participants and how immersion in creative work might teach in non-didactic ways to indeterminate but also to transformative ends, as the artists themselves describe it. Our insight at this point is that disability-affirmative artistic processes create an inter- and intra-relational space that invites generative learning through self- and critical reflection. As Rice et al. (2016) propose, story making methodologies in disability art spaces, whether using methods of film or theatre, create opportunities for artists to interrogate received representations of difference and to generate vital new meanings through mining their embodied experiences. During Small Acts workshops and rehearsals, performers carefully brought forth dimensions of experiences of difference - sensory, stirring, unique, poetic, confronting, and even absurd - previously unacknowledged and unknown. While engaging in a process of excavating and shaping the newly felt and grasped into creative gifts, performers re-engage with their histories in unpredictable and generative ways, often discovering elements of their selves and lives that otherwise would remain untapped. The creation of disability art results in 'making sense' of a range of mundane/surprising, painful/pleasurable, disavowing/affirming, ugly/beautiful and tragic/funny elements of embodied human experience, culminating in new knowledge and insight for performers themselves (and potentially for audiences). Consistent with the insights of performance artists including Arsenault (2012), Maddalena (2009), and Sprinkle (1997), the 'magic' of artistic practice that implicates the self lies in the permission it gives makers to envision and experiment with feelings, sensations, gestures, embodied moments, memories, imaginings, and ideas, such that these 
become de- and re-constructed as they did in Small Acts. Perhaps unique to disability arts, this making/remaking has fundamental implications for imagining the human anew, offering a vision of humanity premised not on sameness but on difference.

The collaborative nature of Small Acts enriched these processes of discovery. Though not without tensions and challenges, the collective approach to artistic creation gave per-formers' insights into unique and shared experiences of difference, which in turn expanded pedagogical possibilities for individual and collective understanding. Consistent with Rice et al. (2016)'s insights into story making in disability affirmative spaces, the sharing of story through the stages of researching, writing and performing often blurred boundaries between selves and others. By taking risks with the self, working with expanding notions of accessibility, and discussing new insights as these surfaced, per-formers located themselves in each other's evolving narratives, and critically reflected on their own in relation to others' experiences. In many ways, the creative space facilitated 'imaginal knowing' (Leonard and Willis 2008). This allowed performers to learn about themselves in and through difference while simultaneously scaffolding a shared sense of disability experience and culture. In this way, the artistic processes that culminated in Small Acts invited different sorts of transformations from therapeutic ones. We found that disability art spaces like the one generated here where disabled people are not understood as broken and in need of fixing - can allow affirmative and expanded conceptualizations of difference and of the human to emerge. By making generative relational spaces that orient to disability as a fertile site of knowledge, disability artists intervene in humanist notions of the human and reconfigure bodies and minds of difference in vibrant new ways that assert the vitality of disabled lives and of disability culture.

\section{Disclosure statement}

No potential conflict of interest was reported by the authors.

\section{Notes on contributors}


Gail J. Mitchell is Professor of Nursing at York University in Toronto, Canada. She collaborates with teams using research-based drama in order to critique the discourses and images portraying persons diagnosed with dementia and embodied difference. Dr. Mitchell and her collaborators offer models for relational, arts-based practices.

Carla Rice is Professor in the College of Social and Applied Human Sciences at the University of Guelph, Guelph, Canada. As Founding Director of Re•Vision: The Centre for Art and Social Justice and Principal Investigator \& Co-Director, Bodies in Translation, her scholarship is a transformative force for disrupting stereotypes and societal barriers.

Victoria Pileggi is affiliated with the Department of Family Relations and Applied Nutrition at the University of Guelph, Guelph, Canada. Her scholarship focuses on child-parent relations. She works with the $\mathrm{Re} \bullet \mathrm{Vision}$ team as a research associate.

\section{References}

Anderson, S., J. Fast, N. Keating, J. Eales, S. Chivers, and D. Barnet. 2016. "Translating Knowledge: Promoting Health through Intergenerational Community Arts Programming." Health Promotion Practice 18 (1): 1-11. doi:10.1177/1524839915625037.

Arsenault, N. 2012. "A Manifesto of Living Self-Portraiture (Identity, Transformation, and Performance)." Canadian Theatre Review 150: 64-69.

Boal, A. 2000. Theater of the Oppressed. London, UK: Pluto Press.

Boydell, K. M. 2011. "Making Sense of Collective Events: The Co-Creation of a Research-Based Dance." Forum Qualitative Sozialforschung/Forum Qualitative Social Research, 12, Art. 5.

Burton, R. 2017. "Playing the Long Game: Some Pros and Cons of Working Collaboratively." Canadian Theatre Review 170: 40-43.

Cahnmann-Taylor, Melisa. 2008. "Histories and New Directions." In Arts-based Inquiry in Diverse Learning Communities: Foundations for Practice, edited by Melisa 
Cahnmann, and Richard Siegesmund, 3-15. London: Routledge.

Camic, P. M., E. L. Baker, and V. Tischler. 2016. "Theorizing How Art Gallery Interventions Impact People with Dementia and Their Caregivers." The Gerontologist 56: 1033-1041. doi:10.1093/ geront/gnv063.

Carley, M. S. 1996. "Teambuilding: Lessons from the Theatre." Training \& Development 50 (8): 41-43. Chandler, E., N. Changfoot, C. Rice, A. LaMarre, and R. Mykitiuk. 2018. "Cultivating Disability Arts in Ontario." Review of Education, Pedagogy, and Cultural Studies, 40 (3): 249-264.

Conquergood, D. 2002. "Performance Studies: Interventions and Radical Research." TDR/The Drama Review 46: 145-156.

Cox, S. M., P. Brett-MacLean, and C. A. Courneya. 2016. "'My Turbinado Sugar': ArtMaking, Well-Being and Professional Identity in Medical Education." Arts \& Health 8: 65-81.

Dupuis, S. L., P. Kontos, G. Mitchell, C. Jonas-Simpson, and J. Gray. 2016. "ReClaiming Citizenship through the Arts." Dementia 15: 358-380.

Felshin, S. 1995. "The Athena Language Learning Project NLP System: A Multilingual System for Conversation-Based Language Learning." In Intelligent Language Tutors: Theory Shaping Technology, edited by V. M. Holland, J. D. Kaplan, and M. R. Sams, 257-272. Mahwah, NJ: Lawrence Erlbaum Associates, Publishers. Fiorella, L., and R. E. Mayer. 2016. "Eight Ways to Promote Generative Learning." Educational Psychology Review 28 (4): 717-741.

Freire, P. 1972. Pedagogy of the Oppressed. 1968. Translated by Myra Bergman Ramos. New York: Herder.

Golosky, O. M. 2017. "Power in a 'Safe' Space." Canadian Theatre Review 170: 35-39.

Gray, J. A. 2016. "An Aesthetic of Relationality: Exploring the Intersection of Embodiment, Imagination and Foolishness in Research-Informed Theatre." Doctoral diss., University of Toronto, Canada. https://tspace.library.utoronto.ca/bitstream/1807/76493/3/Gray_Julia_A_ 201611_PhD_thesis.pdf.

Howard, L. A. 2004. "Speaking Theatre/Doing Pedagogy: Re-Visiting Theatre of the Oppressed." Communication Education 53 (3): 217-233. 
Jacobson, R., and G. McMurchy. 2010. Focus on Disability and Deaf Arts in Canada:

Report from the Field. Ottawa, ON: Canada Council for the Arts.

https://ifacca.org/ko/news/2010/12/15/focus- disability-deaf-arts-canada/.

Johnson, V., and J. Stanley. 2007. "Capturing the Contribution of Community Arts to

Health and Well- Being." International Journal of Mental Health Promotion 9 (2): 28-35.

Kemmis, S., R. McTaggart, and R. Nixon. 2013. The Action Research Planner. New York, NY: Springer. doi:10.1007/978-981-4560-67-2.

Kinsella, E. A. 2003. "Toward Understanding: Critiques of Reflective Practice and Possibilities for Dialogue." Canadian Association for the Study of Adult Education, Online Proceedings. http:// www.casaeaceea.ca/ casae/sites/casae/archives/cnf2003/2003_papers/rtannekinsellaCAS03. pdf.

Kramer, L. A., and J. F. Fask. 2017. "Creative Collaborations through Inclusive Theatre and Community Based Learning, Palgrave Studies." Play, Performance, Learning, and Development. doi:10.1057/978-1-137-59926-1_5.

Kuppers, P. 2011. Disability Culture and Community Performance. New York: Palgrave Macmillan. Kuppers, P. 2016. "Diversity: Disability." Art Journal 75 (1): 93-97.

Lariscy, N. 2016. "Staging Stories That Heal: Boal and Freire in Engaged Composition." Community Literacy Journal 11 (1): 127-137.

Leonard, T., and P. Willis. 2008. "Introduction." Chap. 1 In Pedagogies of the imagination: Mythopoetic Curriculum in Educational Practice, edited by T. Leonard and P. Willis, pp. 1-8. Dordrecht: Springer.

Mackey, S. 2016. "Applied Theatre and Practice as Research: Polyphonic Conversations." Research in Drama Education: The Journal of Applied Theatre and Performance 21 (4): 1-14.

Maddalena, C. J. 2009. "The Resolution of Internal Conflict through Performing Poetry." The Arts in Psychotherapy 36 (4): 222-230.

Mitchell, D., S. Snyder, and L. Ware. 2014. '“[Every] Child Left Behind': Curricular Cripistemologies and the Crip/Queer Art of Failure." Journal of Literary and Cultural Disability Studies 8 (3): 295-314. 
Nedlund, A.-C., and J. Nordh. 2015. "Crafting Citizen(ship) for People with Dementia: How Policy Narratives at National Level in Sweden Informed Politics of Time from 1975 to 2013." Journal of Aging Studies 34: 123-133.

Perry, M. 2011. "Theatre and Knowing: Considering the Pedagogical Spaces in Devised Theatre." Youth Theatre Journal 25 (1): 63-74. doi:10.1080/08929092.2011.569461.

Platt, S. 1997. "Art and Activism: A Brief History." Art Papers 21 (3): 18-20.

Raphael, R. 2013. "Art and Activism: A Conversation with Liz Crow." Journal of Visual Art Practice 12 (3): 329-344.

Rice, C., E. Chandler, E. Harrison, M. Ferrari, and K. Liddiard. 2015. "Project Re•Vision: Disability at the Edges of Representation." Disability \& Society 30 (4): 513-527.

Rice, C., E. Chandler, K. Liddiard, J. Rinaldi, and E. Harrison. 2016. "The Pedagogical Possibilities for Unruly Bodies." Gender \& Education. Advanced online publication. doi:10.1080/09540253.2016. 1247947.

Rice, C., E. Chandler, J. Rinaldi, K. Liddiard, N. Changfoot, R. Mykitiuk, and I. Mundel. 2017. "Imagining Disability Futurities." Hypatia: A Journal of Feminist Philosophy 32 (2): 213-229.

Rice, C., A. LaMarre, and R. Mykitiuk. 2018. "Cripping the Ethics of Disability Arts Research." In The Palgrave Handbook of Ethics in Critical Research, edited by C. I. Macleod, J. Marx, P. Mnyaka, and G. Treharne, 257-272. London: Palgrave.

Rice, C., and I. Mundel. 2018. "Multimedia Storytelling Methodology: Notes on Access and Inclusion in Neoliberal Times." Canadian Journal of Disability Studies, forthcoming.

Sagan, Olivia. 2017. "Thou Art, I am: Discovery and Recovery in the Art Making Process." In Applied Practice: Evidence and Impact in Theatre, Music and Art. Applied Theatre, 172-189. London: Bloomsbury Methuen. ISBN 9781474283847. Sajnani, N. 2012. "The Implicated Witness: Towards a Relational Aesthetic in Dramatherapy." Dramatherapy 34 (1): 6-21.

Sajnani, N. 2013. "The Body Politic: The Relevance of an Intersectional Framework for 
Therapeutic Performance Research in Drama Therapy." The Arts in Psychotherapy 40: 382-385.

Sprinkle, A. 1997. "Some of My Performances in Retrospect." Art Journal 56 (4): 6870. doi:10.2307/ 777728.

White, V., and G. Belliveau. 2011. "Multiple Perspectives, Loyalties and Identities: Exploring Intrapersonal Spaces through Research-Based Theatre." International Journal of Qualitative Studies in Education 24 (2): 227-238.

Yassi, A., J. B. Spiegel, K. Lockhart, L. Fels, K. Boydell, and J. Marcuse. 2016. "Ethics in Community- University-Artist Partnered Research: Tensions, Contradictions and Gaps Identified in an 'Arts for Social Change' Project." Journal of Academic Ethics 14 (3): 1-22.

Zwicky, J. 2017. Wisdom \& Metaphor. Edmonton, AL: Brush Education. 